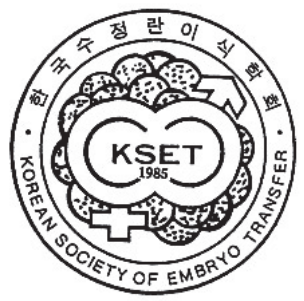

\title{
Patterns of Ovarian Changes Associated with Surge Mode Secretion of Gonadotropin in Dairy Cows with Cyclic Estrous Cycle
}

\section{Seung-Joon $\mathrm{Kim}^{\dagger}$}

College of Veterinary Medicine, Kyungpook National University, Daegu 41566, Republic of Korea

\section{Abstract}

The purpose of the present study was to determine the elaborate characteristics of ovarian changes including follicles and corpus luteum, and hormonal patterns of gonadotropin surge mode secretions during the normal consecutive estrous cycle in three dairy cows. Non-lactating and multiparous Holstein cows $(n=3)$ used as experimental animals. The cows were assigned to examine the relationship among ovarian changes (follicle, corpus luteum), ovarian steroids (estradiol, progesterone) and gonadotropin (LH, FSH) surge mode secretion during the successive estrous cycles by rectal palpation, ultrasonography and hormonal assay. The mean length of the estrous cycle for the three cows was $23.1 \pm 1.44$ days $( \pm$ SEM), with a range of 20-28 days. In six estrous cycles, the number of two follicular waves, three follicular waves and four follicular waves was 2, 3 and 1, respectively. The sequential ultrasonographic monitoring showed that the corpus luteum with $\geq 10 \mathrm{~mm}$ in diameter detected from Day 2 (Day 0 is ovulation) in six estrous cycles of all cows. Preovulatory increases in estradiol concentration reached $10.36 \pm 1.10 \mathrm{pg} / \mathrm{ml}$ on the 2 days before ovulation of the last dominant follicle. All cows exhibited a preovulatory rise in estradiol concentration followed by a typical preovulatory LH and FSH surge. The mean interval from the peak of LH/FSH surge to ovulation of the last dominant follicle was $31.3 \pm 1.76 \mathrm{~h}$ ( \pm SEM). In these results, each dairy cow showed that ovarian morphological changes and gonadotropin surge mode secretion will be regulated by various environmental factors including age, breeds, nutrition, breeding conditions, etc.

Received : 13 December 2018

Revised : 17 December 2018

Accepted : 18 December 2018

Key Words : Ovary, Estradiol, Progesterone, Gonadotropin surge.

† Correspondence: Seung-Joon Kim (ORCID: 0000-0002-8521-8898)

Tel: +82-53-950-5971, Fax: +82-53-950-5994

E-mail address: kjoon00@knu.ac.kr 


\section{INTRODUCTION}

Estrous cycle consists of a series of predictable reproductive events beginning at estrus and ending at the subsequent estrus. They are continued throughout the adult female life and interrupted by pregnancy, nursing and by season of the year in some species. Cyclicity also would be ceased under pathologic condition, such as inadequate nutrition, uterine infection and ovarian disorders.

The physiological characteristics of estrous cycle have been well established in domestic ruminants. The length of the estrous cycle averages 21 days in cows and 20 days in heifers (range, 18-24 days), averages 16.5-17.5 days in ewes (range, 14-18 days) and averages 20.4 days in goats (range, 19-21 days) [Gordon, 1997; Gordon, 1996]. The duration of estrous cycle has many various morphological events including development of follicles, ovulation, conformation and regression of luteal tissue [Donaldson and Hansel, 1965; McNeilly et al., 1981; Rajakoski, 1960; Sirois and Fortune, 1988]. The estrous cycle is divided into two distinct phases, which are named after the dominant structure present on the ovary during each phase of the cycle. The divisions of the estrous cycle are the "follicular phase" and the "luteal phase".

The follicular phase is the period from the regression of corpora lutea to ovulation. During the follicular phase, primary ovarian structures are preovulatory follicles. The characteristics of follicular changes during the estrous cycle are characterized as wave-like developments in most ruminant animals. For example, there are two to four waves of growth of follicles during bovine estrous cycles [Pierson and Ginther, 1988; Pierson and Ginther, 1984]. Among the emergence of the successive follicular waves, the dominant follicles of last follicular wave produce the dominant reproductive hormone, estradiol, and destined for estrous behavior and ovulation.

The luteal phase is the period from ovulation until corpora lutea regression. The ovulation of the dominant follicle caused to rise the formation of luteinization. During the luteal phase, the dominant ovarian structures are the corpora lutea and the primary reproductive hormone is progesterone. The luteal phase can be further divided into following three stages; increasing stage of progesterone in early luteal phase, maintain the plateau of progesterone levels in functional luteal phase and decreasing stage of progesterone in regression phase of corpus luteum [Peters, 1985].

Thus, it can be summarized that the follicular phase and the luteal phase appear by turns during the estrous cycle of domestic ruminants. The ovary can send the information about the status of estrous cycle to the target organs by the secretion of estradiol from the ovulatory follicles and of progesterone from the corpora lutea.

Until now, it has been well known that the central factor for the regulation of ovarian dynamics and functions is hypothalamic gonadotropin releasing hormone $(\mathrm{GnRH})$, the neurodecapeptide, which regulates gonadotropin secretion from pituitary gland during the estrous cycle of mammals including domestic ruminants [de la Cruz A et al., 1976; Foster and Ryan, 1981; Johnson and Advis, 1985; Lucy and Stevenson, 1986; Yen, 1977]. The GnRH stimulates the pituitary gonadotroph producing luteinizing hormone (LH) and follicle-stimulating hormone (FSH) [Martin, 1984], and this gonadotropin regulate the ovarian function, such as follicular growth and maturation, ovulation, corpus luteum formation and maintenance [McNeilly et al., 1986]. Recently, some neural electrophysiological and endocrinological studies clearly demonstrated that the GnRH is regulated by two distinct hypothalamic generators, the "pulse generator" and the "surge generator" [Mori et al., 1991]. The GnRH pulse generator governs the pulsatile gonadotropin secretion from the pituitary by the pulsatile discharge of GnRH into hypophyseal portal circulation, and the activated GnRH pulse generator stimulates the follicular growth and estradiol secretion by stimulating of gonadotropin secretion during the follicular phase. On the other hand, the GnRH surge generator is driven by the elevated concentration of estradiol from the preovulatory follicles, and induces a large amount of GnRH release, namely GnRH surge. Then the GnRH surge induces LH surge for ovulation.

Interestingly, several studies indicated that the pattern of FSH secretion is not partly in agreement with that of LH secretion. Namely, a fluctuation of GnRH concentration in hypothalamic level caused the surge mode secretion of both $\mathrm{LH}$ and FSH, demonstrating that the preovulatory FSH surge is controlled by the same mechanisms that produce the coincident LH surge [Crowder and Nett , 1984; Huang and Miller, 1980]. However, we need to study more thoroughly for the various morphological and hormonal events in the period of normal estrous cycle. Therefore, we conducted to determine the detailed characteristics of ovarian dynamics, ovarian steroid hormonal changes and peripheral gonadotropin surge mode secretion during the normal consecutive two estrous cycles in dairy cows. 


\section{MATERIALS AND METHODS}

\section{Animals}

Non lactating and multiparous Holstein cows $(n=3)$ from Tokyo University of Agriculture and Technology, 6 to 7 years of age, weighing 550 to $650 \mathrm{~kg}$ were examined for one to two estrous cycles before the start of experiment and showed normal and regular cycles. Three animals which were maintained indoors with tie stall system, were fed hay, silage and concentrates and were allowed to have water ad libitum, were approached by the manual of Field Science Center of Tokyo University of Agriculture and Technology.

\section{Ovarian rectal palpation and ultrasonography}

Ovarian changes were examined in two successive estrous cycles by rectal palpation and ultrasonography to determine the ovulation, the duration of estrous cycle, follicular dynamics (sizes and numbers of follicles $\geq 5 \mathrm{~mm}$ in diameter) and the formation and regression of the corpus luteum. Ultrasonographic images were basically monitored every two days throughout the estrous cycles and daily from Day 14 of the first estrous cycle to Day 12 of the second estrous cycle, and at three hours interval from Day -1 (Day 0 is the day of ovulation) to the confirmation of ovulation of Day 0. Ultrasonography were equipped with a 5-MHz intrarectal probe (SUPEREYE SSD-500, Fujihira Industry Co., Tokyo, Japan) connected to a real-time B-mode linear array ultrasound scanner. All examinations were recorded with video image printer and reviewed later.

\section{Follicles and corpus luteum analysis}

During the ultrasonographic examination, all follicles $\geq 5 \mathrm{~mm}$ in diameter and the feature of corpus luteum were monitored. The following definitions were used in this study and had been adapted from the previous studies [Ginther et al., 1989; Sirois and Fortune, 1988]. The term "wave" was used to signify the follicular growth $\geq 5 \mathrm{~mm}$ in diameter, either singularly or as part of a group of follicles. The day of emergence of a wave was assigned to the day that at least one follicle of the wave was detected. The dominant follicle of a wave was defined as the one that grew to at least $8 \mathrm{~mm}$ and exceeded the diameter of all other follicles in the wave. The estrous cycle was also classified by the number of follicular wave into the following groups: (1) two follicular waves (first wave with a dominant anovulatory follicle and second wave with a dominant ovulatory follicle); (2) three follicular waves (first and second waves with a dominant anovulatory follicle and third wave with a dominant ovulatory follicle); (3) more than three follicular waves.

\section{Blood Sampling}

Blood sampling $(10 \mathrm{ml})$ for progesterone and estradiol determinations was collected by carrying out daily jugular venipuncture through the two subsequent estrous cycles. For determination of LH and FSH surges, blood samples $(5 \mathrm{ml})$ were collected at 2-h intervals in the first estrous cycle from the regression of corpus luteum until the succeeding ovulation of the ovulatory dominant follicle, which detected by rectal palpation and ultrasonography. The catheter (14 gauge; outside diameter, $2.0 \mathrm{~mm}$; MEDICUT Catheter Kit, Sharwood Co., Tokyo, Japan) was fixed into jugular vein one day before the start of frequent blood sampling for analysis of the gonadotropin pulse and surge in the three cows. The catheter was filled with saline with heparin $(10 \mathrm{IU} / \mathrm{ml})$ to prevent the coagulation. At each frequent sampling time, $2 \mathrm{ml}$ of fluid were withdrawn from the catheter and discarded, the sample collected, and the catheter filled with $3 \mathrm{ml}$ of heparinized saline. Blood samples were stored at $4^{\circ} \mathrm{C}$ and centrifuged at $3000 \mathrm{rpm}$ for $20 \mathrm{~min}$, and then plasma was stored at $-20^{\circ} \mathrm{C}$ until assayed for progesterone, estradiol-17 b (estradiol) and gonadotropin, including LH and FSH.

\section{Hormone assays}

Plasma concentrations of progesterone and estradiol were assayed by double-antibody radioimmunoassays (RIAs) method using ${ }^{125}$ I-labeled radioligand, as previously described [Taya et al., 1985]. Antiserum against progesterone (GDN 337) and estradiol17b (GDN 244) were used. The mean sensitivity of the assays for progesterone and estradiol were $0.016 \mathrm{ng} / \mathrm{ml}$ and $0.83 \mathrm{pg} / \mathrm{ml}$, respectively. The intra- and inter-assay coefficients of variation were $9.01 \%$ and $4.8 \%$ for progesterone and $9.83 \%$ and $10.45 \%$ for estradiol, respectively.

Bovine LH concentrations in plasma were measured by a double-antibody RIA using ${ }^{125}$ I-labeled radioligand. The following ligands were used; USDA-bLH-I-1 (U.S. Department of Agriculture, U.S.A) for radioiodination and USDA-bLH-B-1 as a standard, and the following reactors were utilized; anti-ovine LH rabbit serum (YM No. 18) as the first antibody and goat anti-rabbit immunoglobulin as the second antibody. The sensitivity of the assay was $0.04 \mathrm{ng} / \mathrm{ml}$. The intra- and inter-assay coefficients 
of variation were $12.67 \%$ and $19.7 \%$, respectively.

Bovine FSH concentrations in plasma were measured by a double-antibody RIA, using the modulated method of the previous report [Bolt and Rollins, 1983]. The following ligands were used USDA-FSH-B1 for radioiodination and USDA-FSH-B1 (AFP-5600, USDA) as a standard, and the following reactors were utilized; anti-bovine FSH b serum (USDA-5-pool) as the first antibody and goat anti-rabbit immunoglobulin as the second antibody. The sensitivity of the assay was $0.29 \mathrm{ng} / \mathrm{ml}$. The intra- and inter-assay coefficients of variation were $12.6 \%$ and $14.2 \%$, respectively.

\section{Statistical Analyses}

Basically, all data were analyzed using the Scheffe method of analysis of variance with the StatView computer program (StatView 4.5; Abacus Concepts Inc., Berkeley, CA). Data are presented as mean \pm SEM. The LH and FSH surges were defined as the point when a sustained rise (for at least two consecutive points of blood sampling) in the plasma LH and FSH concentrations exceeded twice the average baseline level before the surge mode of LH and FSH secretion.

\section{RESULTS}

\section{Ovarian follicular dynamics and plasma estradiol level}

The ovarian dynamics and plasma ovarian steroids levels of the three animals during the two consecutive cycling estrous cycles are shown in Figure 1. The mean length of the estrous cycle for the three cows was $23.1 \pm 1.44$ days ( \pm SEM), with a range of 20-28 days (Table 1). In six estrous cycles, the number of two follicular waves, three follicular waves and four follicular waves was 2, 3 and 1, respectively. The mean intervals from the emergence of dominant ovulatory follicle to the ovulation of the dominant follicle was 10 days in two follicular waves group, 4.6 days in three follicular waves group and 5 days in four follicular waves group, respectively. Follicles grown to $\geq$ $5 \mathrm{~mm}$ in diameter emerged on 0.5 and 10 days for first and second wave, respectively, in two follicular waves, and on 2, 9.3 and 18.7 days for first, second and third wave, respectively, in three follicular waves, and on 0, 8, 16 and 22 days, respectively, in four follicular waves. Preovulatory increases in plasma estradiol concentration reached $10.36 \pm 1.10 \mathrm{pg} / \mathrm{ml}$ on the 2 days before ovulation of the last dominant follicle. All cows exhibited a preovulatory rise in estradiol concentration followed by a typical preovulatory LH and FSH surge. Moreover, the plasma estradiol concentration increased gradually in early luteal phase from Day 2 after ovulation, peaked around on Day 4 and then decreased and maintained at a basal level until the preovulatory peak of estradiol concentration during the estrous cycles. The mean level of the plasma estradiol on Day 4 reached $5.16 \pm 0.54 \mathrm{pg} / \mathrm{ml}$ (mean $\pm \mathrm{SEM}$ ) and this level was significantly different during the luteal phase $(P<0.05)$.

\section{Changes of corpus luteum and progesterone}

The sequential ultrasonographic monitoring showed that the corpus luteum with $\geq 10 \mathrm{~mm}$ in diameter detected from Day 2 in six estrous cycles of all cows (Figure 1). The diameter of all corpora lutea increased and reached to maximum size during the early luteal phase (on Day 2-10). The maximum size maintained during the functional luteal phase and then regressed rapidly. In all cycles, a cavity at the center of the corpus luteum appeared and remained for 4-7 days, and then gradually filled in and disappeared. Plasma progesterone concentrations increased gradually from Day 2 to Day 8-10 (range: $0.9-13 \mathrm{ng} / \mathrm{ml}$ ). The increased progesterone concentration was maintained for 6-11 days during

Table 1. General parameters, including cycling estrous cycle length, the number of follicular wave and time from corpus luteum regression or LH surge to ovulation in three cows

\begin{tabular}{|c|c|c|c|c|}
\hline & Cow A & Cow B & Cow C & Mean \pm SEM \\
\hline $\begin{array}{l}\text { Cycle length } \\
(2 \text { cycles, d) }\end{array}$ & 23,20 & 20,21 & 28,27 & $23.7 \pm 1.44$ \\
\hline $\begin{array}{l}\text { Follicular wave } \\
\text { ( } 2 \text { cycles, d })\end{array}$ & 3,2 & 3,2 & 4,3 & $2.83 \pm 0.30$ \\
\hline $\begin{array}{l}\text { Days from CL regression } \\
\text { to ovulation }\end{array}$ & 5 & 4 & 6 & $5.0 \pm 0.57$ \\
\hline $\begin{array}{c}\text { Times from peak of } \\
\text { LH surge to ovulation }(h)\end{array}$ & 34 & 28 & 32 & $31.3 \pm 1.76$ \\
\hline
\end{tabular}



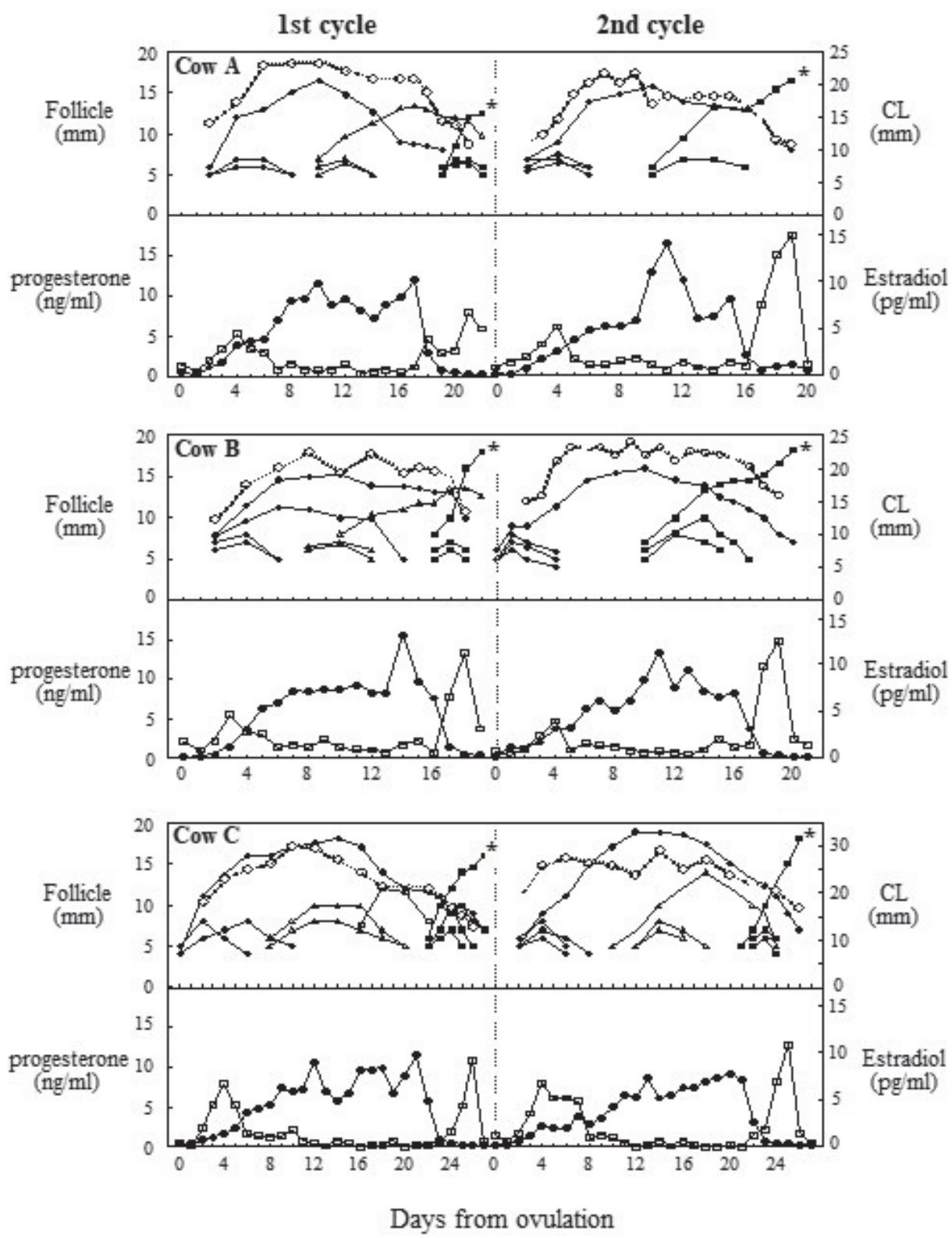

Figure 1. Patterns of follicular development (1), diameter of corpus luteum $(\propto)$ and plasma concentrations of progesterone (1: bottom panel in each cow) and estradiol (o) hormones during the two consecutive estrous cycles of the three cows (Cow A, Cow B and Cow C). The upper figures in each cow describe the growth and regression of individual follicles with antral diameters $5 \mathrm{~mm}$ or more (each line with black indexes depicts an individual follicle) and diameters of corpus luteum on both ovaries (each line with open cycles). The lower figures in each panel illustrate peripheral concentrations of estradiol and progesterone. The asterisk indicates the day of ovulation in each estrous cycle.

the luteal phase and then decreased rapidly. Although the decrease of progesterone concentration in the late luteal phase was more rapid than the regression of corpus luteum diameter, there was a parallel relationship between corpus luteum diameter and progesterone concentration during the estrous cycle. The time interval from the start of regression of corpus luteum to ovulation was $5.0 \pm$ 0.57 days ( \pm SEM, Table 1$)$ in the first estrous cycle.

\section{Ovulatory dominant follicle and gonadotropin surge}

The surge modes of LH and FSH secretion occurred simultaneously during each follicular phase of the first estrous cycle (Figure 2). The mean interval from the peak of LH/FSH surge to ovulation of the last dominant follicle was $31.3 \pm 1.76 \mathrm{~h}$ ( \pm SEM; Table 1). The length of estrous cycle differed among the three cows, and the interval between peak of gonadotropin surge and ovulation 

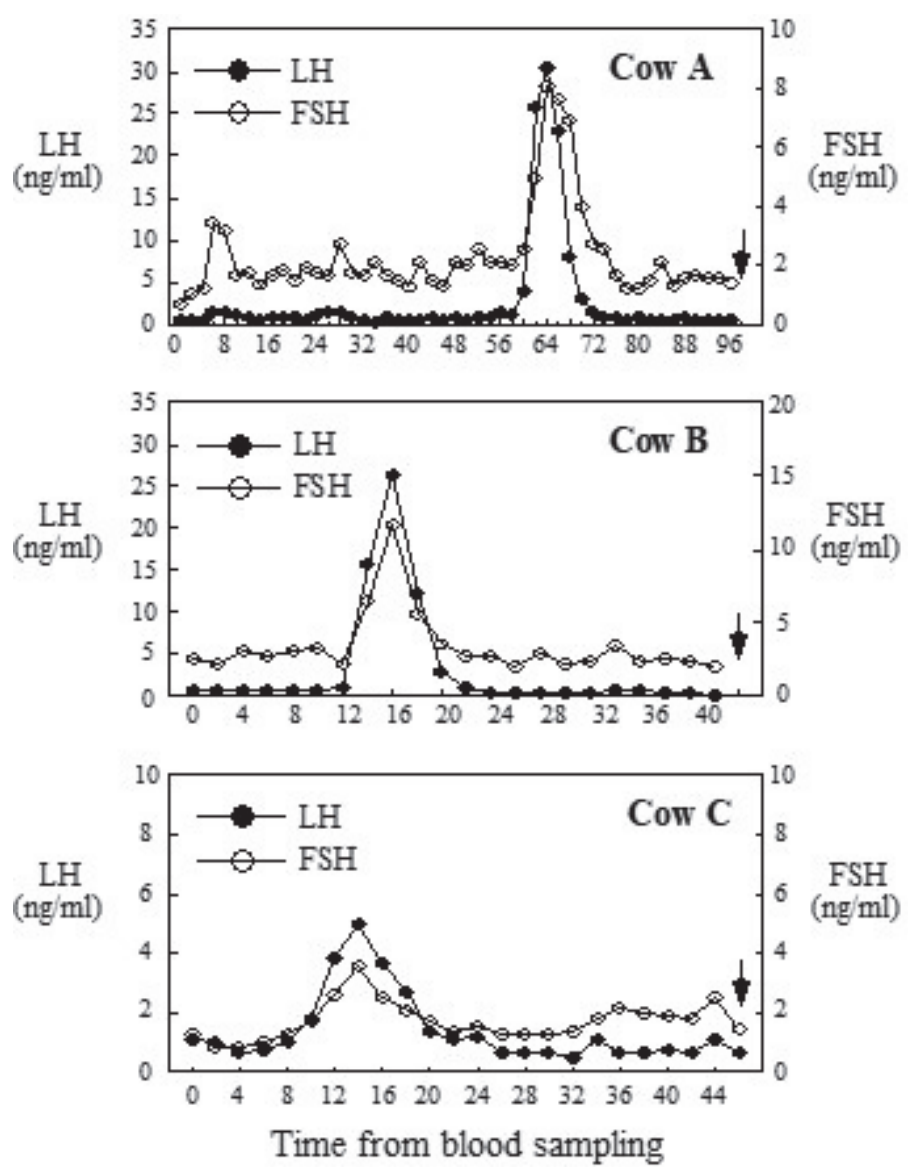

Figure 2. Profiles of plasma concentrations of luteinizing hormone (LH) and follicle-stimulating hormone (FSH) between the next day of confirmation of corpus luteum regression and ovulation in three cows (Cow A, Cow B and Cow C). Arrows indicate the time of ovulation confirmation.

is similar in 3 cows. The maximum diameter of dominant follicle just before ovulation was $12.5 \mathrm{~mm}, 18 \mathrm{~mm}$ and $16 \mathrm{~mm}$ in Cow $\mathrm{A}$, Cow B and Cow C, respectively (Figure 1).

\section{DISCUSSION}

The results of the present study are consistent with previous reports that the subtle and gradual increases of progesterone in the early and functional luteal phase suppressed the pulsatile frequency of LH but not FSH [Walters et al., 1984]. Specifically, the present study strongly demonstrated that LH pulsatile frequency is decreased in a dose dependent manner by peripheral progesterone concentration in the early luteal phase (from Day 2 to Day 8). Also, our results showed that the increase of estradiol concentration in the early luteal phase (e.g. 4 days after ovulation) was associated with high frequency of LH, suggesting that pulsatile frequency of LH above 4 pulses/8h degree plays a major role in controlling estradiol production from the dominant follicle in the early luteal phase.
In the present study, the follicular dynamics during the estrous cycle is similar to that reported previously [Driancourt et al., 1991; Fortune, 1994] in normal cycling cows. In the estrous cycles with three and four waves, large non-ovulatory follicles present at the beginning of luteolysis during the follicular phase and the growing preovulatory dominant follicle ovulated about 5 days after the emergence of the last dominant follicle. The maximum size of dominant ovulatory follicle was not different from that of dominant follicle of first wave. However, the dominant follicle of the second wave is smaller than that of dominant follicle of both first and third waves in the cases with three follicular waves (Figure 1), in agreement with previous report [Fortune et al., 1988; Pierson and Ginther, 1984]. In most ruminant animals, it is well established that the elevation of estradiol in preovulatory phase may be induced by high frequency of LH pulse via the absence of negative feedback mechanism of progesterone [Richter et al., 2002; Walters et al., 1984], indicating that LH pulsatile frequency may be an important key to produce estradiol from the dominant follicle. This result also showed that several- 
fold increase of estradiol followed by the synchronous surges of $\mathrm{LH}$ and FSH, and then induced the ovulation in all animals nearly $30 \mathrm{~h}$ after from the peak of LH surge activated by the positive feedback mechanism of estradiol during the follicular phase, as previously reported [Mori and Kano, 1984]. Although some studies reported that concentration of estradiol elevated on the around 4 days after ovulation is higher than that of the other period of luteal phase [Walters et al., 1984] in agreement with the present results, those results had not suggested directly the possibility that high frequency of LH pulse may have role to increase the peripheral estradiol concentration from the dominant follicle of the first wave. In this regard, this result clearly demonstrated that increased peripheral estradiol concentration would be produced on conditions with not only the size of follicle larger than $8 \mathrm{~mm}$ but also the period of early luteal phase in the bovine estrous cycle. Furthermore, this result showed that the peripheral estradiol concentration could not be produced by dominant follicles larger than $8 \mathrm{~mm}$ during the functional luteal phase when progesterone concentration in peripheral levels were higher than $4 \mathrm{ng} / \mathrm{ml}$, suggesting that high progesterone concentration would not effect the estradiol production.

Although, many studies showed that dairy cows have various duration of estrous cycles in the same breeding conditions, suggesting each reproductive physiology of cows regulated by diverse artificial and natural environmental factors. This study suggested that the full investigation in two continuous estrous cycle of dairy cows will be valuable foundations in the field of regulation of gonadotropin secretion by ovarian steroid hormones in domestic ruminants.

In conclusion, these results demonstrate clearly that surge modes of LH and FSH secretion was regulated by peripheral progesterone and estradiol concentrations during the normal estrous cycle, especially the period of late follicular phase. Also, we need to study more relationship among the ovarian dynamics, gonadotropin pulsatile secretion patterns and ovarian steroid hormones during the normal estrous cycles in dairy cows.

\section{ACKNOWLEDGMENT}

I want to thank Drs. Tomomi Tanaka, Hideo Kamomae, Gen Watanabe, Tokyo University of Agiculture and Technology for the great help and supports.

\section{REFERENCES}

Bolt DJ and Rollins R. 1983. Development and application of a radioimmunoassay for bovine follicle-stimulating hormone. J. Anim. Sci. 56: 146-154.

Crowder ME and Nett TM. 1984. Pituitary content of gonadotropins and receptors for gonadotropin-releasing hormone $(\mathrm{GnRH})$ and hypothalamic content of GnRH during the preovulatory period of the ewe. Endocrinology 114: 234-239.

De la Cruz A, Arimura A, de la Cruz KG, Schally AV. 1976. Effect of administration of anti-serum to luteinizing hormonereleasing hormone on gonadal function during the estrous cycle in the hamster. Endocrinology 98: 490-497.

Donaldson L. and Hansel W. 1965. Histological study of bovine corpora lutea. J. Dairy Sci. 48: 905-912.

Driancourt MA, Thatcher WW, Terqui M. Andrieu D. 1991. Dynamics of ovarian follicular development in cattle during the estrous cycle, early pregnancy and in response to PMSG. Domest. Anim. Endocrinol. 8: 209-221.

Fortune JE. 1994. Ovarian follicular growth and development in mammals. Biol. Reprod. 50: 225-232.

Fortune JE, Sirois J, Quirk SM. 1988. The growth and differentiation of ovarian folicles during the bovine estrous cycle. Theriogenology 29: 95-109.

Foster DL and Ryan KD. 1981. Endocrine mechanisms governing transition into adulthood in female sheep. J. Reprod. Fertil. Suppl. 30: 75-90.

Ginther OJ, Kastelic JP, Knopf L. 1989. Composition and characteristics of follicular waves during the bovine estrous cycle. Anim. Reprod. Sci. 20: 187-200.

Gordon I. 1997. Controlled reproduction in farm animals. vol.

2. Controlled reproduction in sheep and goats. pp. 53-397. Cap International, Oxon, UK.

Gordon I. 1996. Controlled reproduction in farm animals, vol. 1. Controlled reproduction in cattle and buffaloes. pp. 100-132. Cap International, Oxon, UK.

Huang ESR and Miller WL. 1980. Effects of estradiol-17beta on basal and luteinizing hormone releasing hormone-induced secretion of luteinizing hormone and follicle stimulating hormone by ovine pituitary cell culture. Biol. Reprod. 23: 124-134.

Johnson AL and Advis JP. 1985. Changes in luteinizing hormonereleasing hormone content of discrete hypothalamic areas associated with spontaneous and induced preovulatory luteinizing hormone surges in the domestic hen. Biol. Reprod. 32: 813-819.

Lucy MC and Stevenson JS. 1986. Gonadotropin-releasing hormone 
at estrus: luteinizing hormone, estradiol, and progesterone during the periestrual and postinsemination periods in dairy cattle. Biol. Reprod. 35: 300-311.

Martin GB. 1984. Factors affecting the secretion of luteinizing hormone in the ewe. Biol. Rev. Camb. Philos. Soc. 59: 1-87.

Matton P, Adelakoun V, Couture Y, Dufour JJ. 1981. Growth and replacement of the bovine ovarian follicles during the estrous cycle. J. Anim. Sci. 52: 813-820.

McNeilly AS, Jonassen JA, Frase HM. 1986. Suppression of follicular development after chronic LHRH immunoneutralization in the ewe. J. Reprod. Fertil. 76: 481-490.

Mori Y and Kano Y. 1984. Changes in plasma concentrations of $\mathrm{LH}$, progesterone and oestradiol in relation to the occurrence of luteolysis, oestrous and time of ovulation in the Shiba goat (Capra hircus). J. Reprod. Fertil. 72; 223-230.

Mori Y, Nishihara M, Tanaka T, Shimizu T, Yamaguchi M, Takeuchi Y, Hoshino K. 1991. Chronic recording of electrophysiological manifestation of the hypothalamic gonadotropin-releasing hormone $(\mathrm{GnRH})$ pulse generator activity in the goat. Neuroendocrinology 53: 392-395.

Peters AR. 1985. Hormonal control of the bovine oestrous cycle.

I. The natural cycle. Br. Vet. J. 141: 564-575.

Pierson RA and Ginther OJ. 1988. Ultrasonic imaging of the ovaries and uterus in cattle. Theriogenology 29: 21-37.

Pierson RA and Ginther OJ. 1984. Ultrasonography of the bovine ovary. Theriogenology 21: 495-505.

Rajakoski E. 1960. The ovarian follicular system in sexually mature heifers with special reference to seasonal, cyclical and left-right variations. Acta. Endocrinol. (Suppl 52). 34: 7-68.

Richter TA, Robinson JE, Evans NP. 2002. Progesterone blocks the estradiol-stimulated luteinizing hormone surge by disrupting activation in response to a stimulatory estradiol signal in the ewe. Biol. Reprod. 67: 119-125.

Sirois J and Fortune JE. 1988. Ovarian follicular dynamics during the estrous cycle in heifers monitored by real-time ultrasonography. Biol. Reprod. 39: 308-317.

Taya K, Watanabe G, Sasamoto S. 1985. Radioimmunoassay for progesterone, testosterone and estradiol-17 beta using ${ }^{125}$ I-iodohistamine radioligands [in Japanese]. Jpn. J. Anim. Reprod. 31: 186-196.

Walters DL, Schams D, Schallenberger E. 1984. Pulsatile secretion of gonadotrophins, ovarian steroids and ovarian oxytocin during the luteal phase of the oestrous cycle in the cow. J. Reprod. Fertil. 71: 479-491.

Yen SS. 1977. Regulation of the hypothalamic-pituitary-ovarian axis in women. J. Reprod. Fertil. 51: 181-191. 